\title{
HACIA UNA MACROSINTAXIS DEL ADJETIVO CALIFICATIVO
}

\author{
TOWARDS A MACRO-SYNTAX OF THE ADJECTIVE
}

\author{
José García PÉRez \\ Universidad de Sevilla \\ jgarciap@us.es
}

Recibido: 24/04/2019

Aceptado: 16/10/2019

\begin{abstract}
Resumen
El presente trabajo tiene por objetivo analizar las posibles funciones macroestructurales (enunciativa, modal, informativa, argumentativa) que cumple el adjetivo calificativo cuando aparece como enunciado independiente y establece, siguiendo la terminología propuesta por C. Fuentes, una vinculación de metadiscurso-discurso con los enunciados con los que se relaciona. Comprobaremos así que el ámbito de alcance del adjetivo no se restringe solo al sustantivo y, al mismo tiempo, ampliaremos el concepto de macrosintaxis, hasta ahora centrado en la periferia del enunciado, al abordar las relaciones entre enunciados, algo que también es clave para la fijación de elementos o estructuras que terminan siendo marcadores discursivos. Nuestra metodología es, pues, la Lingüística Pragmática. Para el análisis que se sigue se han utilizado tanto los materiales que proporciona el Corpus MEsA como algunos testimonios de la prensa escrita española, recogidos entre mayo y
\end{abstract}

\begin{abstract}
The aim of this article is to analyse adjectives in terms of macro-struture functions. Only adjectives which function as an independent unit are analysed. These are the adjectives that, according to C. Fuentes, create a metadiscourse link between them and other related sentences. Thus, it is proved that adjectives do not just function with a noun. At the same time, the macro-linguistic concept, which has been analysed in terms of statement, is expanded. In order to do this, relationships between sentences are studied. This is also the key to set structures which become discursive markers. Pragmatics is our methodology. Materials from the Corpus MEsA and some testimonies from the written Spanish press haven been used for the following analysis. Those testimonies were collected between May and June in 2018. Morever, in order to ensure coherence, references to Pedro Sánchez's censure motion in that period haven been used as well.
\end{abstract}

Para citar este artículo / To cite this article: García Pérez, José (2019): "Hacia una macrosintaxis del adjetivo calificativo". González Sanz, Marina y Pérez Béjar, Víctor (eds.): ELUA: Macrosintaxis en construcción, Anexo VI, págs. 91-109.

Enlace/Link: http://dx.doi.org/10.14198/ELUA2019.ANEXO6.06 
junio de 2018 y, para asegurar la cohesión temática, referentes a la moción de censura propiciada por Pedro Sánchez en ese mismo periodo.

PALABRAS CLAVE: adjetivo; enunciado; macrosintaxis; argumentación; valoración.
KEY WORDS: adjective; statement; macrosyntax; argumentation; assessment.

\section{INTRODUCCIÓN}

Hasta el momento, el potencial discursivo del adjetivo solo ha sido abordado desde su presencia en el sintagma nominal. Por un lado, hay autores que han sostenido que con la anteposición el adjetivo no especifica, no añade semas al sustantivo, sino que el hablante lo antepone para expresar su subjetividad, para indicar la forma en la que quiere que el receptor se enfrente a la entidad valorada. Así lo propone Ó. Flórez (1995) con la distinción del uso referencial y del uso atributivo para diferenciar entre anteposición para el primero y posposición para el segundo en el sistema (estándar) del español:

4. La diferencia lógico-semántica del adjetivo, aceptada como esencial tanto por la gramática tradicional como por los exponentes de la gramática generativa y corrientes opuestas (Flora Klein-Andreu entre otros), de explicar un referente ya especificado o delimitado. cuando aparece antes del sustantivo (de «caracterizarlo simplemente» sin contrastarlo o diferenciarlo, según Klein), y de delimitar o especificar el referente del sustantivo cuando va postpuesto («caracterizándolo contrastivamente», diferenciándolo de los demás referentes de su clase, según la hipótesis de Klein), pensamos que, en el fondo, tiene su origen en un factor pragmático: en la intención del hablante de usar el adjetivo «referencialmente», o sea, presuponiendo la existencia del referente de la expresión nominal a la que modifica, con el fin de explicarlo aumentando su intensión; o «atributivamente», es decir, sin tener en su mente dicha presuposición en el momento de la comunicación. En este último caso, el hablante usa el adjetivo para especificar o delimitar la extensión del referente de la expresión nominal en el momento en que esta se enuncia. La manera de atraer la atención del oyente y de indicarle el uso por el cual ha optado en un caso concreto, es la posición en la que el hablante realiza fonéticamente el adjetivo: antepuesto, para el uso «referencial»; y postpuesto. para el uso «atributivo» (Flórez 1995: 167).

Por su parte, C. Fuentes (2006) considera la anteposición "una perspectiva o forma de presentar su contenido semántico [del sustantivo], no añadir[le] características". A diferencia del adjetivo pospuesto, que sí restringe la extensión del sustantivo, "el adjetivo antepuesto implica un realce especial" que permite la expresión de "dimensiones marginales" como la modalidad o la orientación o fuerza argumentativa:

El adjetivo puede anteponerse para resaltar o focalizar una afirmación (epíteto), donde se muestran valores subjetivos. Pero también puede emplearse a veces para expresar una coordenada desde la que entender el sustantivo. Es un marco, que lo envuelve. No le añade semas, sino que indica la perspectiva desde la que mirarlo: subjetividad, determinación, argumentación, enfatización de la intensión, adecuación a la referencia o denotación... Esto supondría la consideración de dos puntos de inserción sintáctica del adjetivo: uno subordinado al sustantivo, y otro constituyendo con él el grupo nominal, núcleo del sintagma (Fuentes Rodríguez 2006: 1307). 
Además, todos esos valores de perspectiva sobre el adjetivo (modal, argumentativo, etc.) pueden darse simultáneamente, dado el "espacio multidimensional" en el que nos movemos cuando tenemos en cuenta la expresión de la subjetividad del hablante. De ahí que haya unidades que sirvan para expresar a la vez orientación argumentativa y valoración:

Las unidades se transfieren de un plano a otro, en un proceso de adelgazamiento significativo: del contenido léxico de dimensión a la cuantificación, de la valoración a la orientación argumentativa... (Fuentes Rodríguez 2006: 1307).

Efectivamente, estos planteamientos parten de lo que siempre ha venido considerando la gramática tradicional, y todavía hoy se mantiene en la Nueva Gramática (2009): con la anteposición el adjetivo restringe la intensión del nombre, mientras que con la posposición lo que se restringe es la extensión:

13.2.1a Los modificadores adjetivos pueden RESTRINGIR la extensión del sustantivo, como en gatos negros, día claro, pero también pueden DESTACAR, PONDERAR o EVALUAR un rasgo de su significado, como en misteriosos gatos, claro día, [...]. El grupo nominal gatos negros tiene una extensión más reducida que la del sustantivo: denota, en efecto, un subconjunto de la extensión de gatos, puesto que quedan excluidos de esta los gatos que no son negros. El papel de negros en este ejemplo es, por tanto, el de un adjetivo RESTRICTIVo. En cambio, en los misteriosos gatos, el adjetivo misteriosos es un modificador no restrictivo que se aplica a todas las entidades designadas por el sustantivo gatos destacando o ponderando la propiedad de 'ser misteriosos' como rasgo inherente de la clase de los gatos. (NGLE 2009: 238)

Sin embargo, ya Rafael Lapesa (1975) apuntó que en la elección de la posición entraban en juego otros factores además de la subjetividad del hablante:

La oposición entre especificación objetiva, intelectual, y valoración subjetiva, afectiva, es factor esencial, pero no único, para la colocación del adjetivo calificativo románico respecto al sustantivo (Lapesa 1975: 330).

Aunque, a lo largo de la historia del español se registran más casos de anteposición para el realce expresivo, este es igual de efectivo con la posposición:

Si el adjetivo no especifica, sino que añade al sustantivo una explicación no imprescindible para entender a qué ser un objeto dado se refiere, se sitúa muy frecuentemente antes del sustantivo; la cualidad atribuida queda así realzada. [...] La anteposición n oes forzosa; en todo tiempo alterna con ella el uso contrario: "Ojos vellidos catan a todas partes" (Cid, 1612); "el canto del cigno, que se tiende sobre la yerua rociada" (Lapesa 1975: 332)

Y es que hay factores del contexto gramatical que están por encima de esa introducción de subjetividad a la hora de elegir la posposición, como el número de adjetivos que acompañan al nombre o la presencia de modificadores tanto en el sustantivo como en el adjetivo:

En la colocación del adjetivo atributivo influyen circunstancias contextuales de carácter sintáctico: que en vez de un solo adjetivo haya dos o más, adjuntos al mismo sustantivo; 
que el adjetivo lleve modificaciones o complementos; que los tenga, por su parte, el sustantivo; carácter y estructura de los modificadores o complementos; que el sustantivo sea común o propio, etc. (Lapesa 1975: 337)

También hay que traer aquí las consideraciones hechas por Violeta Demonte (1982, 1999), quien, además de una rigurosa revisión del estado de esta cuestión, apunta la posiblidad de que la anteposición o la posoposición pueden tener que ver más bien con la naturaleza semántica del adjetivo, de tal manera que las colocaciones sintácticas no van a permitir un uso más o menos subjetivo si el adjetivo no tiene ya esa posibilidad en su intensión. Los únicos que tienen asegurada la anteposición son los llamados "modales" (simple, mero, craso, futuro), mientras que en el resto de clases la aparición antes o después del nombre no tiene por qué seleccionar un valor u otro:

La mayoría de nuestros adjetivos, sin embargo [por contraposición a los modales], son ambiguos entre los dos valores y lo son con independencia de la posición que ocupen. Veamos algunos ejemplos de muy dudosa y difícil interpretación donde aparecen tanto adjetivos relacionales como cualitativos y, de éstos, tanto afectivos como no afectivos:

(21) a. la brisa tibia - la tibia brisa

b. el encargo difícil - el difícil encargo

c. la comida exquisita - la exquisita comida

d. el matorral asfixiante - el asfixiante matorral

e. la nariz respingona - la respingona nariz

f. la guarida amplia - la amplia guarida

g. el estrépito constante - el constante estrépito

h. las meditaciones largas - las largas meditaciones

i. los residuos domésticos - los domésticos residuos

(Demonte 1982: 480-481)

Por otra parte, otro acercamiento bastante interesante a la potencialidad discursiva del adjetivo lo ha hecho la Teoría de la Argumentación de Anscombre y Ducrot (1994), donde algunos de ellos son incluidos, junto con algunos adverbios, en la categoría de modificadores (des)realizantes, que se refiere a aquellos elementos -fundamentalmente léxicos- que tienen la capacidad de aumentar o disminuir la fuerza argumentativa de un elemento. Así lo expresan Anscombre y Ducrot (Anscombre y Ducrot 1994: 265):

Una palabra léxica $\mathrm{Y}$ es desrealizantecon relación a una expresión $\mathrm{X}$ si:

1. La combinación $X+Y$ no es contradictoria.

2. La combinación $X+Y$ tiene una orientación argumentativa inversa de o una fuerza argumentativa inferior a la de $\mathrm{X}$ solo.

Por ejemplo, si tomamos el siguiente diálogo:

-Vaya, no me queda espacio en mi pen drive.

-Yo tengo el disco duro.

El primer hablante puede perfectamente inferir como conclusión que el segundo participante tiene disponibilidad de espacio y le va a ofrecer su disco duro para que almacene 
lo que en su pen drive no puede. Pero si la respuesta hubiera sido "Yo tengo el disco duro lleno" la inferencia hubiera sido justamente la contraria, es decir, en este caso, tener otra forma de almacenamiento, que era lo que se pedía, no tiene para el primer hablante la fuerza argumentativa suficiente para obtener la conclusión de que podrá guardar lo que desea, pues también está copado.

Por su parte, el realizante hace justamente lo contrario, pues aumenta la fuerza argumentativa del enunciado en el que se inserta: "Cuando la combinación $\mathrm{X}+\mathrm{Y}$ tenga la misma fuerza que $\mathrm{X}$ solo y una fuerza superior o igual a la de $\mathrm{X}$, diremos que $\mathrm{Y}$ es realizante con respecto a Y" (Anscombre y Ducrot 1994: 265-266).

Así, partiendo del ejemplo anterior, si el segundo hablante hubiera dicho "Yo tengo el disco duro libre", el primero habría inferido con más intensidad la disponibilidad del disco duro y la intención de ser prestado.

Sin embargo, como ya hemos señalado, en este trabajo no nos limitaremos al estudio del sintagma nominal, puesto que no es la única forma en la que el adjetivo puede tener un potencial pragmático. Tal y como demostraremos, como enunciado independiente el adjetivo extiende su alcance y tiene esa doble función persuasivo-valorativa.

\section{METODOLOGÍA Y CORPUS}

La metodología que usaremos es la Lingüística pragmática, que propone estudiar "la influencia de los factores del entorno en el producto lingüístico y su codificación" (Fuentes Rodríguez 2017a: 50), siguiendo la tendencia en la investigación lingüística de finales del siglo XX. La Lingüística pragmática considera que

el objeto o la unidad máxima es el texto, y hay que entenderlo como un producto interactivo en relación con un contexto amplio. Es decir, hay que estudiar todo aquello que influencia el contexto y que tiene un reflejo en la lengua (Fuentes Rodríguez 2017a: 55).

En nuestro caso, seguimos el modelo propuesto por Catalina Fuentes Rodríguez (2005, 2007, 2012, 2013, 2014, 2015, 2017a, 2017b, 2018), quien en absoluto propone un divorcio entre gramática y pragmática, sino que considera que esta última es una perspectiva de análisis que inserta en el análisis gramatical factores situacionales, proponiendo así la superación de los límites oracionales y trabajar con el concepto de enunciado, formado por un contenido proposicional y una serie de elementos periféricos que se sitúan bien en el margen izquierdo, bien en el derecho, o bien interrumpiendo la linealidad sintáctica, y que aluden al proceso enunciativo, a la expresión de la actitud del hablante, o se encargan de resaltar algún elemento con fines informativos o argumentativos:

Partimos del enunciado como estructura realizada. Corresponde este aun acto de habla expresado en un contexto determinado y dirigido a un oyente. Puede estar formado por una oración, varias, un sintagma o incluso una palabra. Tiene completitud semántica y entonativa. Como estamos hablando de realizaciones en contexto, el enfoque debe incluir la pragmática (Fuentes Rodríguez 2018: 12).

En su sistema de análisis, esta autora propone la segmentación del texto en tres niveles jerárquicos: microestructura (sintaxis, semántica, fonética-fonología), macroestructura 
(texto como unidad) y superestructura (tipología textual elegida). En cada uno de esos tres niveles se reflejan los cuatro planos que muestran la influencia de la situación en el texto: plano informativo, plano argumentativo, plano enunciativo y plano modal. Los dos primeros aluden a la adecuación del texto al receptor: lo que conoce o desconoce (plano informativo) y la forma en que el emisor busca convencerlo (plano argumentativo). Por su parte, los planos enunciativo y modal dan cuenta de la forma en la que el hablante se manifiesta en el texto, bien como organizador de las distintas voces que en él concurren (plano enunciativo), bien como entidad que expresa su subjetividad (plano modal). Así, el enunciado sería la unidad mínima de la macroestructura y la relación entre enunciados a través de conectores/ enlaces o sin ellos- daría lugar a la unidad máxima: el texto. El contenido proposicional iría acompañado de una serie de operadores discursivos que aludirían a todos esos contenidos que anclan lo dicho a la situación y momento de la enunciación. El esquema de enunciado que ella propone es el siguiente:

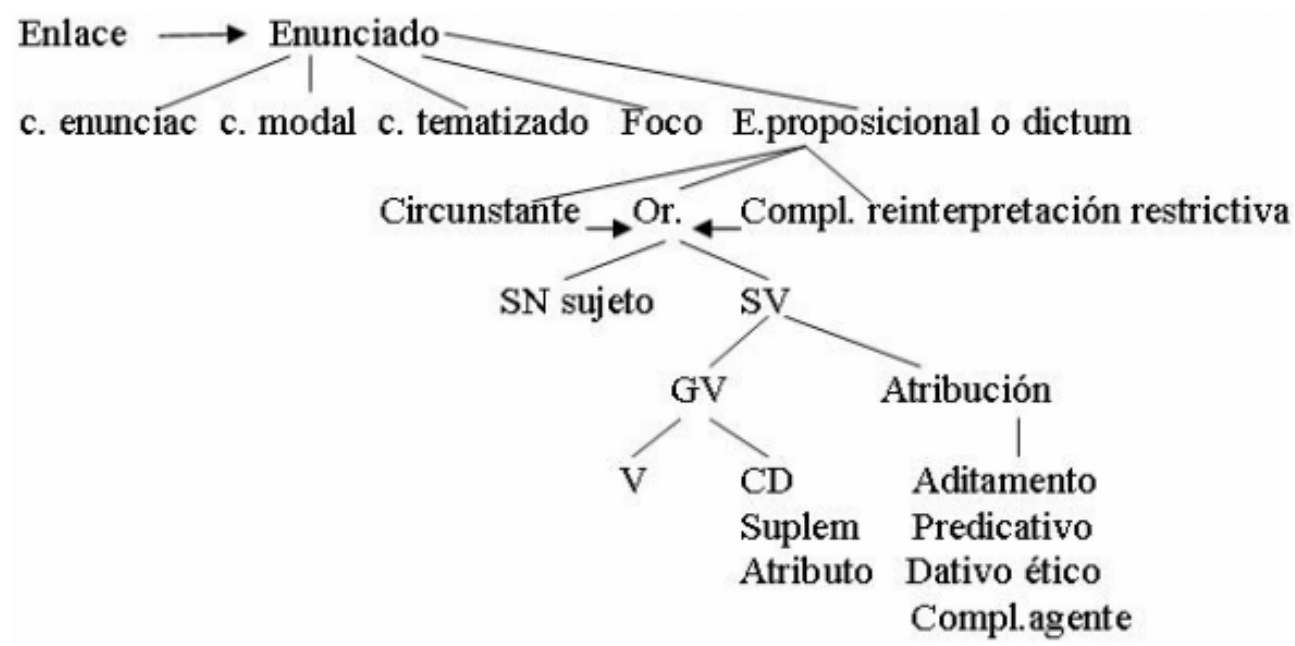

Ilustración 1. Estructura del enunciado según Fuentes Rodríguez (2017b: 16)

Sin embargo, en sus últimas consideraciones, esta autora señala que, en muchas ocasiones, esos contenidos macroestructurales que enmarcan lo dicho no se encuentran en la periferia del enunciado como operadores o como lo que se han venido llamando comment clauses (Quirk, R. et al 1985), sino que las expresiones de modalidad, cariz argumentativo, etc. pueden estar en enunciados independientes, autónomos, de tal manera que se hace necesario dar el salto y pasar de la descripción del enunciado como estructura a la explicación de las relaciones entre enunciados dentro del texto. Esto se da especialmente en aquellos casos en los que no existen conectores discursivos entre ellos, y tampoco son válidos los criterios de la sintaxis tradicional/oracional: no hay independencia absoluta (coordinación), ni tampoco interdependencia (subordinación), aunque guardan una relación semántico-pragmática clara y que no tiene nada que ver con la cohesión, que es el único tipo de relación entre enunciados hasta ahora identificado, pues, "en suma, también los enunciados pueden actuar como marco de otro enunciado" (Fuentes Rodríguez 2018: 102). 
En nuestro caso, al utilizar la perspectiva macrosintáctica para el análisis del adjetivo, encontramos ocasiones en las que la evaluación (subjetividad) puede expresarse en un enunciado formado solamente por un adjetivo. Por ejemplo, la valoración de un individuo en el siguiente tweet:

\section{(1) Alberto Garzón (@agarzón):}

Yo no creo en patrias ni en música militar. Los pobres no tienen patria, y los ricos esconden sus intereses detrás de cualquier bandera.

Usuario 105 (hombre):

Por eso se te cae la baba con mandatarios como Maduro o los Castro, militares militaristas con la patria en la boca. @agarzon .Hipócrita. (Corpus MesA, Twitter)

El adjetivo aparece aislado, separado por pausas y al final de una réplica, indicando que el hablante tiene al político Alberto Garzón por hipócrita debido a que, por un lado, se opone al desfile militar del 12 de octubre en España, pero, por otro, apoya a dictaduras militares como la cubana o la venezolana. Además, esa posición final en enunciado independiente tiene el carácter de una conclusión. En otras ocasiones no se trata de la persona, sino que la evaluación se dirige hacia los propios contenidos dictales precedentes en la interacción:

\section{(2) Usuario 19 (hombre):}

$\mathrm{Y}$ en las respuestas al tweet que da la noticia justifican los insultos. Increíble. Ismael Serrano Retwitteó EL PAIÍS EL PAÍS@el_pais Amenazan e insultan a una mujer por señalar que todos los Nobel 2016 son hombres [enlace] En @verne

El modelo del que partimos también tiene en cuenta el género textual, llamado superestructura. Por ello, atendiendo a la importancia de este aspecto, en nuestro trabajo analizaremos un género discursivo: las redes sociales, concretamente Twitter y Facebook a partir de los materiales proporcionados por el Corpus MEsA, que cuenta con una amplia muestra del uso del español actual en diferentes redes sociales (Twitter, Facebook, Instagram, Youtube, Whatsapp, diferentes blogs, webs y foros), ordenada adecuadamente para el análisis filológico. Con ello queremos reivindicar el discurso de las redes sociales como campo de investigación para acercarnos a la conversación tecnológica (Sáez 2007, Yus 2010), no solo por ser un ámbito -más- de relación comunicativa, sino porque, además, es prácticamente el más extendido hoy en día en las sociedades occidentales a pesar, como se ha dicho, de ser canales de comunicación muy recientes. En ese sentido, hay que tener en cuenta que, si bien hay géneros discursivos en la red que se avienen, aunque con diferencias, a otros tradicionales (el chat con la conversación, el correo electrónico con la carta), las apariciones de redes sociales "llevan a la convergencia e hibridación de géneros, lo cual requiere nuevos métodos de investigación en este terreno" (Mancera Rueda y Pano Alamán 2013: 13). En efecto, son parte del fenómeno conocido como Web 2.0 o Web social que, a diferencia de la Web 1.0, en la que los dueños del espacio eran los únicos que podían introducir y actualizar el contenido, la Web 2.0 está "centrada en la interoperabilidad entre plataformas, el diseño en torno al usuario, y la colaboración e intercambio de todo tipo de datos" (Mancera Rueda y Pano Alamán 2013: 23). Así, como ocurre en cualquier sociedad o grupo humano, también en estos espacios virtuales "se busca establecer relaciones sociales, compartir información y revitalizar, reforzar y expandir las redes existentes” (Mancera Rueda y Pano Alamán 2013: 
12). De ahí que, aunque haya una diferencia entre identidad real y virtual, puesto que estas plataformas permiten la creación de perfiles alternativos, "no es posible mantener identidades inventadas durante mucho tiempo, pues el personaje inventado acaba identificándose con el propio yo 'real'” (Mancera Rueda y Pano Alamán 2013: 12).

Al mismo tiempo, y siendo conscientes de que muchos de los fenómenos lingüísticos vienen determinados precisamente por la tradición discursiva en la que se utilizan -de ahí la importancia de que Fuentes la tenga en cuenta en su modelo- hemos incluido en nuestro corpus de análisis otro género textual que también favorezca la expresión de la subjetividad del hablante, pero que perteneciera o que estuviera más cerca de la distancia comunicativa, pues en las redes sociales lo que predominan son las interacciones en el polo de la inmediatez. Por eso, hemos seleccionado unos cincuenta artículos de tres periódicos de tirada nacional diferentes (El Mundo: 13 editoriales y 20 artículos; El País: 8 editoriales y 43 artículos; y eldiario.es: 41 entradas del blog "Zona crítica") relacionados todos ellos temáticamente con la moción de censura de Pedro Sánchez entre los meses de mayo y junio del pasado año. Con ello queremos asegurarnos de que, cuando identifiquemos un fenómeno en ambos géneros textuales, podamos concluir que ese comportamiento gramatical -y discursivo- tiene un alto grado de generalización en el español, al menos de España ${ }^{2}$, sin que existan notables diferencias en función de la variación, en este caos diamésica.

\section{ANÁLISIS}

En primer lugar, hemos de decir que los casos son bastante más frecuentes en las redes sociales que en los artículos de opinión, donde apenas encontramos unos ocho casos, por lo que ya podemos considerar que se trata de un fenómeno más ligado a la inmediatez, coloquial. Por otra parte, cuando se habla de la posibilidad de que el adjetivo introduzca la subjetividad del hablante, hemos creído conveniente tener en cuenta hacia dónde se dirige esa subjetividad, que en nuestro caso puede estar orientada, mayormente, a la evaluación sobre una entidad determinada (tema de la conversación, objeto, individuos, grupos, etc.) $)^{3}$ :

(3) (FB) Usuario 7 (hombre):

Se cagó en susprincipios,porsalvar suculto,deleznable!!

(4) (FB) Usuario 11 (hombre):

Los que Roban la Justicia les hace pagar tarde o temprano, dejad de meter en el Mismo saco a todo un partido ,ya sé que en Andalucía nadie robo nada en 35años, los20.000 folios y los años de instrucción delaJueza Alaya es un invento de la tele verdad? Precioso

(5) (FB) Usuario 28 (hombre):

Muchos de mis amigos gays votan al pp .... No se entiende pero cierto es ..... Inexplicable.

2 Para una consideración del comportamiento discursivo de los adjetivos en el español de América véase Hummel (2012).

3 Los ejemplos respetan la disposición original del texto tal y como lo ha escrito el hablante, incluyendo faltas de ortografía y unión de palabras. 
(6) (FB) Usuario 4 (hombre):

Estoy tranquilo excepto con la multa que me han puesto snavda de Portugal cuando aún no han cambiado las placas de 70 a 50.Muy triste.

(7) (TW) Usuario 20 (hombre):

Los Simpson predijeron primero lo de Trump y ahora lo de Rita Barberá. Impresionante. [fragmento de un vídeo de 'Los Simpsons' en el que Hommer canta la muerte de una bruja de camino a un funeral mientras Marge le pide algo de respeto]

(8) (TW) Usuario 43 (hombre):

Increíble . Gano la ignorancia, el odio, el racismo, la discriminación, la xenofobia. Ganó \#Trump. \#EleccionesEEUU2016 \#Trump

(9) (TW) Usuario 25 (hombre):

Es así como@usa demuestra estar plagada de sicópatas, enfermos, retrógradas, xenofobicos, racistas! ...triste y preocupante \#TrumpPresident

(10) (TW) Usuario 63 (hombre):

En un nuevo aniversario de la caída del Muro de Berlín ganó Trump. Irónico, justo uno que quiere levantar muros \#TrumpPresident \#TrumpWIN

(11) (TW) Usuario 18 (hombre):

@ Albert_Rivera El Ministro hace su trabajo y tú le estás haciendo el juego a los separatistas y dando votos a Podemos. Lamentable.

(12) (TW) Usuario 6 (mujer):

@greenpeace_esp@Greenpeace por muy premios novel que sean tienen un precio,no es ciencia, es defensa de un mercado, lamentable

(13) (TW) Usuario 28 (no identificado):

(a)Albert_Rivera díselo a De Alfonso el comenta que tu le dabas apoyo a cambio de "algo" para torpedear partidos IndepesFEO Y ANTIDEMOCRÁTICO

(14) (El País) ha preferido pasar a la historia como un presidente que ha sido expulsado en lugar de uno que dimitió. Lamentable.

(15) (El País) Tenía que buscar los votos necesarios para que salieran de una vez. Normal; nada que criticar. Los vascos le piden "cosas" a cambio. Normal; nada que criticar.

En primer lugar, hay que resaltar que la mayoría de los ejemplos identificados corresponden a valoraciones negativas, algo usual en este tipo de redes, y sobre todo en la temática de las conversaciones, que casi siempre versan de política. Para poder abordar el comportamiento es necesario tener en cuenta que en este nivel macroestructural del enunciado la multidimensionalidad es casi inherente, pues, como veremos, estos adjetivos, no solamente tienen una dimensión valorativa (plano modal), sino también persuasiva (plano argumentativo). En efecto, en varios de sus trabajos, C. Fuentes hace hincapié en esta idea en el campo de la pragmática, para el adjetivo en particular, y para el resto de elementos "extraoracionales" en general: 
Las unidades [adjetivos] se transfieren de un plano a otro, en un proceso de adelgazamiento significativo: del contenido léxico de dimensión a la cuantificación, de la valoración a la orientación argumentativa... (Fuentes Rodríguez 2006: 1307).

proponer un enfoque modular donde los diferentes apartados se interconectan e interactúan de manera simultánea, partiendo siempre de que toda estructura se pone a funcionar cuando el hablante verbaliza y lleva esa entidad abstracta a la realidad de la comunicación. Por ello, la multidimensionalidad es fundamental en el discurso, una característica connatural a él. [...] La macrosintaxis se caracteriza por la multidimensionalidad y la polifuncionalidad. Son dos rasgos específicos que la definen y que raramente se tienen en cuenta, al menos la primera. Para hablar de multidimensionalidad es necesario aplicar una visión modular. Veámoslo con los datos. Una aposición, por ejemplo, puede usarse con función claramente explicativa (plano enunciativo, en 22) pero también argumentativa (insertar ciertos argumentos que le permiten al hablante generar o hacer inferir ciertas conclusiones) (Fuentes Rodríguez 2017: 12-21)

Así, en nuestro caso tenemos adjetivos valorativos, que expresan un contenido modal, entendiendo por modalidad "la actitud subjetiva del hablante con respecto a lo que se emite" (Fuentes Rodríguez 2004: 123), pero, al mismo tiempo, tienen un papel dentro del esquema argumentativo del texto, normalmente funcionando como conclusión:

\begin{tabular}{|c|c|}
\hline \multicolumn{2}{|c|}{ FUNCIÓN ARGUMENTATIVA-CONCLUSIÓN } \\
\hline EJEMPLO & ESQUEMA \\
\hline $\begin{array}{l}\text { (TW) Usuario } 63 \text { (hombre): } \\
\text { En un nuevo aniversario de la caída } \\
\text { del Muro de Berlín ganó Trump. } \\
\text { Irónico, justo uno que quiere } \\
\text { levantar muros \#TrumpPresident } \\
\text { \#TrumpWIN }\end{array}$ & $\begin{array}{l}\text { ARGUMENTO: } \\
\text { Trump quiere levantar un muro entre EEUU y } \\
\text { México } \\
\text { CONCLUSIÓN-VALORACIÓN: } \\
\text { Es irónico que gane las elecciones justo en el } \\
\text { aniversario de la caída del muro de Berlín }\end{array}$ \\
\hline $\begin{array}{l}\text { (TW) Usuario } 28 \text { (no identificado): } \\
\text { @Albert_Rivera díselo a De } \\
\text { Alfonso el comenta que tu le dabas } \\
\text { apoyo a cambio de "algo" para } \\
\text { torpedear partidos IndepesFEO Y } \\
\text { ANTIDEMOCRÁTICO }\end{array}$ & $\begin{array}{l}\text { ARGUMENTO: } \\
\text { De Alfonso comenta que le dabas apoyo a } \\
\text { cambio informaciones para dañar a partidos } \\
\text { independentistas } \\
\text { TOPOS O LEY DE PASO }{ }^{3} \text { : } \\
\text { En democracia está mal actuar al margen del } \\
\text { debate y los resultados electorales } \\
\text { CONCLUSIÓN-VALORACIÓN: } \\
\text { Lo que hace Albert Rivera y su partido es feo y } \\
\text { antidemocrático }\end{array}$ \\
\hline
\end{tabular}

4 Sobre la noción de 'topos', 'garante' o 'ley de paso' véase Anscombre y Ducrot (1994), Lo Cascio (1997) o Fuentes y Alcaide (2002). 


\begin{tabular}{|c|c|}
\hline $\begin{array}{l}\text { (FB) Usuario } 4 \text { (hombre): } \\
\text { Estoy tranquilo excepto con la } \\
\text { multa que me han puesto snavda } \\
\text { de Portugal cuando aún no han } \\
\text { cambiado las placas de } 70 \text { a } 50 \text {. } \\
\text { Muy triste. }\end{array}$ & $\begin{array}{l}\text { ARGUMENTO: } \\
\text { No se han aún cambiado las placas de } 70 \text { a } 50 \\
\text { TOPOS O LEY DE PASO: } \\
\text { Hay que ir a la velocidad indicada por las } \\
\text { señales } \\
\text { CONCLUSIÓN-VALORACIÓN: } \\
\text { Muy triste que me hayan multado si he respetado } \\
\text { las señales }\end{array}$ \\
\hline $\begin{array}{l}\text { (TW) Usuario } 25 \text { (hombre): } \\
\text { Es así como @usa demuestra estar } \\
\text { plagada de sicópatas, enfermos, } \\
\text { retrógradas, xenofobicos, } \\
\text { racistas! ...triste y preocupante } \\
\text { \#TrumpPresident }\end{array}$ & $\begin{array}{l}\text { ARGUMENTO: } \\
\text { EEUU está lleno de sicópatas, enfermos, } \\
\text { retrógrados, xenófobos y racistas que han hecho } \\
\text { que Trump sea presidente } \\
\text { TOPOS O LEY DE PASO: } \\
\text { Los sicópatas, enfermos, xenófobos, etc. no son } \\
\text { gente buena o son dañinos } \\
\text { CONCLUSIÓN-VALORACIÓN: } \\
\text { EEUU está en una situación triste y preocupante }\end{array}$ \\
\hline
\end{tabular}

Por otra parte, también encontramos que estos adjetivos en enunciados independientes igualmente pueden funcionar como argumentos. Fijémonos en el siguiente fragmento de un artículo de opinión de El País:

(16) El pacto con el $\mathbf{P N V}^{5}$ se ha transformado en el símbolo más definitorio del estilo político que ha desarrollado siempre el Partido Popular. El Gobierno de Rajoy tenía un problema no menor; y era el de aprobar unos Presupuestos que deberían haberse aprobado en septiembre del año pasado. Tenía que buscar los votos necesarios para que salieran de una vez. Normal; nada que criticar. Los vascos le piden "cosas" a cambio. Normal; nada que criticar. Y así logran sacarle a Rajoy 540 millones. Pero que ahora, desde la oposición, trabaje para que ese dinero no vaya al País Vasco es una indecencia.

Los autores-locutores buscan criticar la relación mantenida por el gobierno de Rajoy con el PNV, puesto que primero les han hecho concesiones y ahora, que ya no gobiernan, intentan que el PNV no se beneficie de esos tratos de favor que ellos previamente les han otorgado. No obstante, los autores, en aras de que los lectores-alocutarios admitan sus consideraciones, realizan una serie de concesiones por las que intentan justificar el comportamiento de Rajoy con el PNV durante su gobierno, para que el contraste con lo que hace ahora el PP en la oposición se perciba más grande e incongruente. De ahí que tengamos el uso de normal en enunciado independiente como argumento que impide incluir una crítica a esa acción llevada a cabo por el gobierno:

5 La negrita es de los autores de la publicación. Las cursivas son nuestras. 


\begin{tabular}{|c|c|}
\hline \multicolumn{2}{|c|}{ FUNCIONES ARGUMENTATIVAS-ARGUMENTO } \\
\hline EJEMPLO & ESQUEMA \\
\hline $\begin{array}{l}\text { Tenía que buscar los votos } \\
\text { necesarios para que salieran } \\
\text { de una vez. Normal; nada } \\
\text { que criticar. }\end{array}$ & $\begin{array}{l}\text { ARGUMENTO }_{1} \text { : } \\
\text { Había que buscar apoyos para sacar los presupuestos } \\
\text { ARGUMENTO }_{2} \text {-VALORACIÓN: } \\
\text { Es algo normal (legítimo) en democracia } \\
\text { CONCLUSIÓN: } \\
\text { No hay nada que criticar en la relación entre gobierno del PP } \\
\text { y PNV }\end{array}$ \\
\hline $\begin{array}{l}\text { Los vascos le piden "cosas" } \\
\text { a cambio. Normal; nada } \\
\text { que criticar. }\end{array}$ & $\begin{array}{l}\text { ARGUMENTO }^{1} \text { : } \\
\text { Los vascos piden prerrogativas por apoyar los presupuestos } \\
\text { ARGUMENTO }_{2} \text {-VALORACIÓN: } \\
\text { Es normal que se recompense un apoyo } \\
\text { CONCLUSIÓN: } \\
\text { No hay nada que criticar en la relación entre gobierno del PP } \\
\text { y PNV }\end{array}$ \\
\hline
\end{tabular}

Cabría plantearse en este caso si, dado el semantismo del adjetivo normal, este no estaría funcionando más bien como topos ("lugar común"), que cuando está explícito es llamado por Fuentes y Alcaide (2002) 'base argumentativa', de tal manera que la imposibilidad de la crítica vendría porque, como toda la comunidad acepta que lo normal, en tanto que común y debido, es que un gobierno pacte, a cambio de favores, con otros grupos para aprobar sus presupuestos, no se pueda objetar, en ese sentido, nada a la relación entre el gobierno del PP y el PNV. En cualquier caso, creo que queda patente la rentabilidad argumentativa de estos adjetivos en enunciados independientes, que se combina y surge a raíz de su inherente potencial valorativo, pero es tarea del pragmatista delimitar e identificar todas las posibilidades discursivas que ofrece una unidad al hablante para la expresión de su presencia en la enunciación y su planificación de cara a la interpretación que quiere suscitar en el receptor.

También hemos encontrado casos en los que el adjetivo como enunciado independiente valora toda la intervención precedente del otro interlocutor, de tal manera que el alcance ya no sería solo a un enunciado precedente o antecedente, sino a un conjunto de enunciados, teniendo también un carácter conclusivo:

\begin{tabular}{|l|l|}
\hline \multicolumn{2}{|c|}{ FUNCIONES ARGUMENTATIVAS-CONCLUSIÓN } \\
\hline EJEMPLO & ESQUEMA \\
\hline Jordi Évole: & ARGUMENTO \\
Antes de acabar, el avence del próximo & El próximo programator $:$ \\
Salvados. El caso VAN DER DUSSEN. & persona que estuvo en la cárcel a pesar \\
Por primera vez una televisión entrevista al & de ser inocente \\
protagonista. & ARGUMENTO \\
Usuario 5 (hombre): & Le robaron doce años de su vida, por \\
@jordievoleMuy interesante. Le robaron 12 & estar en la cárcel, y esa experiencia \\
años de su vida y le dejaron destrozado para el & también le marcará el resto de su vida \\
resto. & CONCLUSIÓN-VALORACIÓN: \\
& Es un caso muy interesante \\
\hline
\end{tabular}


Como señalamos anteriormente, no se puede hablar de mera valoración en general, sino que hay que delimitar la dirección de esa evaluación. Los casos más numerosos son los anteriores, en los que la valoración iba dirigida a la entidad (sujeto(s) u objetos) sobre la que versaba la conversación. Pero también podemos encontrar, aunque en menor número, valoraciones dirigidas a contenidos dictales (intervenciones de otros interlocutores) y a los propios participantes. Veamos las primeras:

(17) (TW) Usuario 17 (mujer):

@ierrejon "Suele escribir con boli bic azul". Impresionante, fascinante. Es un dato que todos moríamos por saber. Qué buen periodismo

(18) (TW) Usuario 19 (hombre):

$\mathrm{Y}$ en las respuestas al tweet que da la noticia justifican los insultos. Increíble. Ismael Serrano Retwitteó EL PAÍS EL PAÍS @el_pais Amenazan e insultan a una mujer por señalar que todos los Nobel 2016 son hombres [enlace] En @verne

(19) (TW) Usuario 46 (mujer):

@maberalv En parte será porque el mundo está lleno de respuestas lamentables como las que ha tenido tu tuit. Muy triste en pleno siglo XXI.

(20) (El Mundo) el diario El País ya anunciaba un periodismo nuevo, con otro lenguaje y un titular extraordinario sobre otro miembro del Gobierno: "El ministro Planas, a punto de ser desimputado en un caso de robo de agua en Doñana".

(21) Asombroso. No es que no responda a la verdad. La Fiscalía de Medio Ambiente de Huelva no aprecia delito contra el medio ambiente y es más que probable que lo desimpute. Nunca en los siete días anteriores desde su nombramiento leímos un titular que dijera: "El presidente Sánchez nombra ministro a un imputado por robo de agua en Doñana". El (nuevo ma non troppo) periodismo consiste en explicar a la gente que lord Acton ha resucitado cuando no nos había contado que se hubiera muerto.

De igual manera, también en este caso identificamos funciones argumentativas para estos adjetivos evaluativos. Tomando el último ejemplo, vemos que el autor-locutor concluye que el titular de El País es "asombroso" por la razón (argumento) de que ese mismo periódico no se había hecho eco de la imputación del ministro Planas en el caso del robo del agua, algo que podría haber dañado la imagen del gobierno de Pedro Sánchez -al que el periódico El País es afín- al tener un ministro imputado entre sus filas. En lugar de eso, y por seguir con la línea de favorecer al gobierno socialista, sí que se hace eco de que ese ministro ya no está imputado en esa causa, lo cual favorece la imagen del ministro y, por ende, la del gobierno al que pertenece; maniobra que al autor-locutor le parece asombrosa.

Por último, quedan las valoraciones dirigidas a los propios interlocutores que participan en las interacciones, de tal manera que este tipo de evaluaciones las encontramos fundamentalmente en las redes sociales, pues los artículos de opinión son un género monologal. Así, generalmente nos encontramos tanto con halagos como con insultos que no son vocativos, sino evaluaciones que los hablantes lanzan a otros participantes en función, bien de lo que han dicho, o bien por lo que conocen del comportamiento y actitud del sujeto: 
(22) (TW) Alberto Garzón (@agarzón):

Yo no creo en patrias ni en música militar. Los pobres no tienen patria, y los ricos esconden sus intereses detrás de cualquier bandera.

Usuario 98 (no identificado):

@agarzon Perdona, pero son los burgueses los únicos que se pueden permitir el lujo de no tener patria, no los pobres. Hippie.

Usuario 105 (hombre):

Por eso se te cae la baba con mandatarios como Maduro o los Castro, militares militaristas con la patria en la boca. @agarzon.Hipócrita.

(23) (FB)Álvaro Ojeda:

BUENAS NOCHES....sean felices, y si lo son con lo justo, mucho mejor. Los guerreros también descansamos. Se avecinan cruzadas muy duras en las próximas semanas... y quiero estar a tope. [Fotografía de Álvaro Ojeda frente al mar]

Usuario 35 (hombre):

Alvaro si necesitas un representante yo estoy dispuesto ii Grande

(24) (FB) Usuario 13 (mujer):

Y como siga así....aquí no va a quedar ni el tato... bueno si! Los chinos se quedarán q ya tienen el mercado para ellos solitos y no dan trabajo a nadie.... y los marroquis $\mathrm{q}$ tienen todas las ayudas q los españoles no tenemos. España caca. Yo con este Gobierno también me voy.

Usuario 18 (no identificado):

[mención a usuario 13], estás sembrada. Piensas igual que la ultraderecha de Reino Unido, la que insulta, agrede y humilla a los españoles que allí residen. Patética!! [dos emoticonos de caras llorando de risa]

(25) (FB) Manuela Carmena:

Una semana más, os contamos algunas de las cosas que ha hecho el Ayuntamiento de Madrid: [vídeo]

Usuario 3 (mujer):

Es vez de hacer críticas destructivas( para los que estan debajo de este texto [del de Carmena] $)^{6}$ deberían pensar con las neuronas y agradecer que ahora hay gente honesta, no ladrones y mafiosos que votaron durante 20 años. IGNORANTES:

(26) (FB) Manuela Carmena:

Aquí tenéis el resumen de los últimos días. ¡Que paséis un buen fin de semana! [vídeo] Usuario 10 (mujer):

Con fuerzas de partido, de nuestro ,de UP, vamos juntos a por la casta impidiendo su expansión!

Lucharemos por Futuro, Sanidad, Educación, y que Brilla mi España con pueblo poderoso ,muy Feliz y Generoso !

Usuario 9 (hombre):

No se si te has dado cuenta si la casta sois vosotros tenéis mas dinero en el banco que cualquier trabador y sin haber pegado en vuestra vida un palo al agua viviendo de nuestros padres. Getas

6 Se refiere a los dos usuarios previos a ella que han comentado negativamente sobre la publicación de Carmena, reprochándole que no actúa adecuadamente como alcaldesa, etc. 
Como hemos señalado, en este tipo de valoraciones, encontramos normalmente un insulto o un halago acompañado de la explicación -previa- de por qué se da ese insulto o ese halago, luego sigue habiendo relación entre enunciados, en este caso desde el punto de vista argumentativo: la explicación se presenta como argumento con la suficiente fuerza como para sostener el insulto o el halago, que a su vez es presentado como conclusión tras el argumento de por qué se esgrime tal valoración sobre el interlocutor. De manera más esquemática quedaría así:

\begin{tabular}{|l|l|}
\hline \multicolumn{2}{|c|}{ FUNCIONES ARGUMENTATIVAS-CONCLUSIÓN } \\
\hline EJEMPLO & ESQUEMA \\
\hline $\begin{array}{l}\text { Usuario 98 (no identificado): } \\
\text { @agarzon Perdona, pero son los burgueses } \\
\text { los únicos que se pueden permitir el lujo } \\
\text { de no tener patria, no los pobres. Hippie. }\end{array}$ & $\begin{array}{l}\text { ARGUMENTO: } \\
\text { Son los burgueses los que pueden no tener } \\
\text { patrias, no los pobres como tú dices } \\
\text { CONCLUSIÓN-VALORACIÓN: } \\
\text { Eres un hippie por pensar que no tiene que } \\
\text { haber patrias cuando son necesarias para } \\
\text { proteger a los pobres de los burgueses }\end{array}$ \\
\hline $\begin{array}{l}\text { Usuario 18 (no identificado): } \\
\text { [mención a usuario 13], estás sembrada. } \\
\text { Piensas igual que la ultraderecha de Reino } \\
\begin{array}{l}\text { Unido, la que insulta, agrede y humilla a } \\
\text { los españoles que allí residen. Patética!! } \\
\text { [dos emoticonos de caras llorando de risa] }\end{array}\end{array}$ & $\begin{array}{l}\text { ARGUMENTO: } \\
\text { Te quejas de los chinos en España como Unido la extrema derecha } \\
\text { con los españoles } \\
\text { CONCLUSIÓN-VALORACIÓN: }\end{array}$ \\
$\begin{array}{l}\text { Eres patética por tratar a los extranjeros } \\
\text { igual de mal que tratan a los tuyos fuera de } \\
\text { tu país }\end{array}$ \\
\hline
\end{tabular}

Igualmente, como hemos visto cuando la valoración tenía otra dirección, también en estos casos puede funcionar el adjetivo como argumento. Por ejemplo, en el caso de la respuesta a la publicación de Álvaro Ojeda, el Usuario 35 (hombre), como considera que Álvaro Ojeda es "grande" (argumento), se ofrece a ser su representante (conclusión).

\section{RELACIONES ENTRE ENUNCIADOS}

Una vez que hemos identificado las funciones discursivas que tienen estos adjetivos cuando van en enunciados independientes, nos queda por caracterizar las relaciones que se dan entre estos enunciados y aquellos sobre los que inciden, pues los primeros lo único que hacen es incorporar la presencia del hablante en su enunciación. Sin embargo, como señala C. Fuentes (2018) para el caso de los enunciados parentéticos, nos encontramos con que estos enunciados no están relacionados por medio de los consabidos conectores discursivos. Tampoco sirven los criterios de la sintaxis tradicional porque no hay independencia absoluta

7 Aquí, el uso de este adjetivo se aviene al significado de la primera acepción que de él da el $D E L: 1$. adj. Que supera en tamaño, importancia, dotes, intensidad, etc., a lo común y regular. 
entre ellos (coordinación), ni interdependencia (subordinación), sino que lo que se establece es una relación de tipo semántico-pragmático que surge de tener en cuenta estos contenidos macroestructurales que hasta ahora solo se habían analizado dentro de los márgenes -en la periferia- de cada enunciado. Y es que igualmente el adjetivo en enunciado independiente

Revela una actividad del hablante que aparece como constructor de su discurso controlando la recepción del oyente y la inscripción de cuantos aspectos relativos al propio hablante desea que aparezcan (Fuentes 2018: 227)

Por ello, Fuentes propone entender esta relación entre un enunciado y otro en el que se insertan "las circunstancias macrosintácticas necesarias para su comprensión" (2018: 227) como una relación Discurso-Metadiscurso, una relación de presuposición:

El metadiscurso presupone el discurso sobre el que establece indicaciones de procesamiento. Pero su presencia es optativa. Constituye una estructura relacional, una posibilidad constructiva entre dos enunciados de manera que frente a dos enunciados secuencialmente ordenados, estos establecen una relación en un segundo plano (la de comentario) (Fuentes 2018: 229)

Ya se ha señalado que esto lo indica la autora para las estructuras parentéticas. En nuestro caso, los enunciados sí están secuencialmente ordenados, pero también establecen esa relación de un metadiscurso ("de comentario") con un discurso. Nosotros queremos ampliar esa relación de Metadiscurso-Discurso que C. Fuentes propone para los parentéticos y hacerla extensible al uso de adjetivos que hemos identificado, puesto que también "enunciados completos que se relacionan con otros, en un plano metadiscursivo. El hablante necesita no solo elementos como los conectores que le sirvan para "ligar" el discurso" (Fuentes 2018: 233), lo cual implica que

En macrosintaxis no solo debemos fijarnos en unidades pequeñas que actúan como "prefixes, infixes, suffixes", sino con enunciados completos que se relacionan en este plano. Hay que superar la sintaxis tradicional de la oración, que es insuficiente en estos niveles superiores (Fuentes 2018: 234).

A diferencia de los parentéticos, nuestros adjetivos no interrumpen la linealidad sintáctica ni permiten la inserción de conjunciones, pero igualmente se trata de actos ilocutivos independientes del enunciado base, del que están aislados por pausas -escritas- y expresan un contenido modal-argumentativo. Además, cabe destacar que en nuestro caso el hablante elige una unidad de la microsintaxis: el adjetivo, restringido a su relación con el nombre, para valorar una unidad mayor, como es el enunciado, y en ocasiones un conjunto de enunciados como la intervención, ampliando su alcance (de micro a macrsosintáctico). Así, tomando uno de los ejemplos que hemos aducido, veamos cómo quedaría esa relación entre el discurso o contenido proposicional en un enunciado, y el metadiscurso o contenido extraproposicional en otro:

(27) (TW) Usuario 43 (hombre):

Increíble . Ganó la ignorancia, el odio, el racismo, la discriminación, la xenofobia. Ganó \#Trump. \#EleccionesEEUU2016 \#Trump 


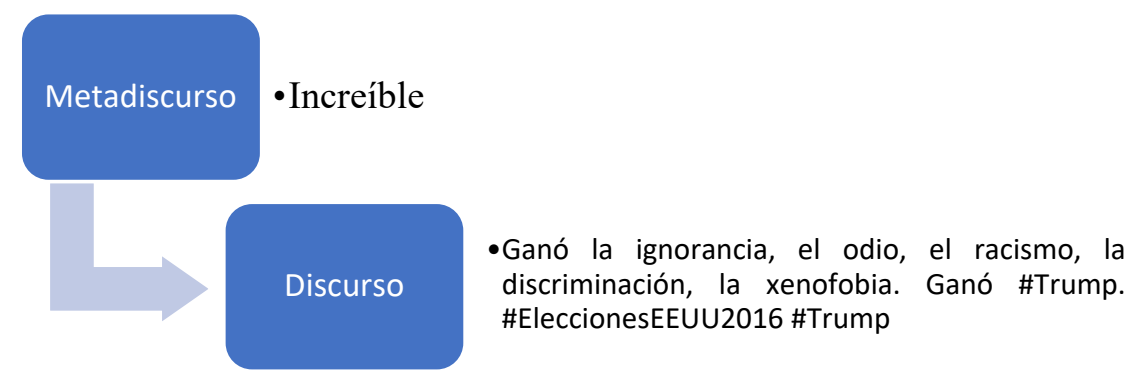

Ilustración 2. Relaciones de Discurso-Metadiscurso

Este esquema difiere del presentado por Fuentes para los parentéticos, que son enunciados que se insertan en el patrón o host del enunciado base al que afectan:

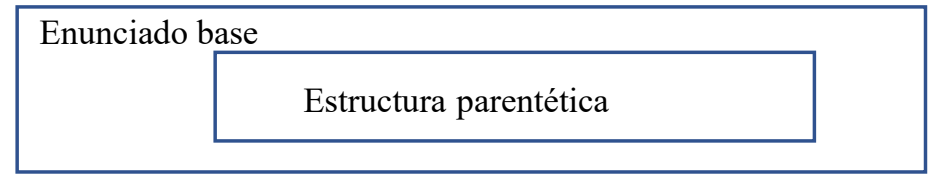

Por último, al igual que lo pretende Fuentes, consideramos que estas funciones que se dan en el nivel de las relaciones entre enunciados tienen que ser equiparadas con las que se pueden dar en la periferia de cada enunciado, ya que ambas expresan los mismos contenidos macroestructurales. Así, además de unidades ya fijadas tanto para enlazar enunciados (conectores) como para introducir marcas pragmáticas (operadores), el sistema también permite que esas mismas marcas pragmáticas (informativas, modales, argumentativas o enunciativas) sean introducidas por enunciados independientes, bien intercalados (parentéticos), bien aparte, fuera del host, que son los que nosotros hemos querido analizar y reivindicar en este trabajo, demostrando que con ellos también estamos ante una "construcción metadiscursiva: el hablante construye el discurso con dos partes y establece relaciones macroestructurales entre ellas" (Fuentes 2018: 236). En muchos casos, señala esta autora, estos enunciados son el primer paso para la gramaticalización de unidades que acaban convirtiéndose en operadores del sistema, pudiéndose postular como primer paso el aislamiento en enunciados independientes, que luego pasarían a estar intercalados (parentéticos) para ir fijándose (comment clauses) y, finalmente, quedar como operadores.

\section{CONCLUSIONES}

A lo largo de este trabajo hemos pretendido llevar a cabo un acercamiento pragmático al adjetivo calificativo a partir del modelo de macrosintaxis propuesto por C. Fuentes, porque teníamos la intuición de que esta categoría podía estar formando parte de estructuras donde su alcance fuera mayor del hasta ahora contemplado (sintagma nominal). Así, hemos comprobado, mediante el análisis de un corpus actual, que el adjetivo calificativo es utilizado como enunciado independiente con un claro fin persuasivo-valorativo (multidimensional) y, a su vez, eso nos ha llevado a la consideración de que esos contenidos macroestructurales no 
tienen por qué ser solo expresados por unidades pertenecientes a la periferia o los márgenes del enunciado. Tal y como ha señalado Fuentes en su último trabajo sobre los parentéticos, que también son estructuras que funcionan como enunciados aparte del que inciden, aunque estos aparecen irrumpiendo la linealidad sintáctica del enunciado base, cosa que en nuestro caso no ocurre, pero el tipo de relación metadiscurso-discurso es la misma. Por ello hemos querido sumarnos a la propuesta de empezar a tener en cuenta el estudio de las relaciones semántico-pragmáticas entre enunciados que escapan a los límites de la sintaxis -y la macrosintaxis- tradicional, porque estas pueden ser una buena vía para explorar posibles fijaciones o procesos de gramaticalización de unidades o estructuras que acaban convirtiéndose en operadores discursivos plenamente integrados en la estructura enunciativa.

\section{REFERENCIAS BIBLIOGRÁFICAS}

Anscombre, J. C. y O. Ducrot (1994). La argumentación en la lengua. Versión española de Julia Sevilla y Marta Tordesillas. Madrid: Gredos.

Demonte, V. (1982). "El falso problema de la posición del adjetivo", Boletín de la Real Academia Española, Tomo 62, Cuaderno 227, pp. 453-486.

Demonte, V. (1999). "El adjetivo: clases y usos. La posición del adjetivo en el sintagma nominal". En Bosque, I. y V. Demonte (dirs.). Gramática descriptiva de la lengua española. Madrid: Espasa.

Flórez, O. (1995). "La posición del adjetivo: una perspectiva pragmática", Dicenda: Cuadernos de filología hispánica, 13, pp. 163-174.

Fuentes Rodríguez, C. y E. R. Alcaide Lara (2002). Mecanismos lingüísticos de persuasión: cómo convencer con palabras. Madrid: Arco Libros.

Fuentes Rodríguez, C. (2004). "Enunciación, aserción y modalidad, tres clásicos", Anuario de Estudios Filológicos, Vol. XXVII, pp. 121-145.

Fuentes Rodríguez, C. (2005). "Hacia una sintaxis del enunciado", Lingüistica Española Actual, Vol. XXVII, no 1 , pp. 35-61.

Fuentes Rodríguez, C. (2006). "Un acercamiento pragmático a la posición del adjetivo". En Casado Velarde, M., R. González Ruiz y M. V. Romero Gualda (eds.). Análisis del discurso: lengua, cultura, valores: Actas del I Congreso Internacional. Madrid: Arco Libros, pp. 1293-1310.

Fuentes Rodríguez, C. (2007). Sintaxis del enunciado: los complementos periféricos. Madrid: Arco Libros.

Fuentes Rodríguez, C. (2012). "El margen derecho del enunciado", RSEL, 42/2, pp. 62-93.

Fuentes Rodríguez, C. (2013). "La gramática discursiva: niveles, unidades y planos de análisis", Cuadernos AISPI, pp. 15-36.

Fuentes Rodríguez, C. (2014). "Los límites del enunciado”, Estudios de Lingüistica del Español, 35, pp. 143-167.

Fuentes Rodríguez, C. (2015). "Nuevos retos en sintaxis del discurso". En Álvarez López, C. J., B. Garrido Martín y M. González Sanz (coords.). Jóvenes aportaciones a la investigación lingüística. Sevilla: Alfar, pp. 35-55.

Fuentes Rodríguez, C. (2017a). Lingüistica pragmática y Análisis del discurso. Madrid: Arco Libros.

Fuentes Rodríguez, C. (2017b). "Macrosintaxis y lingüística pragmática", Círculo de Lingüistica Aplicada a la Comunicación, 71, pp. 5-34.

Fuentes Rodríguez, C. (2018). Parentéticos. Madrid: Arco Libros.

Hummel, M. (2012). Polifuncionalidad, polisemia y estrategia retórica. Los signos discursivos con base atributiva entre oralidad y escritura. Berlin/Boston: De Gruyter.

Lapesa Melgar, R. (1975). "La colocación del calificativo atributivo en español". En Homenaje a la memoria de Don Antonio Rodríguez Moñino: 1910-1975. Madrid: Castalia, pp. 329-346. 
Lo Cascio, V. (1998). Gramática de la argumentación. Versión española de David Casacuberta. Madrid: Alianza.

Mancera, Rueda, A. y A. Pano Alamán (2013). El español coloquial en las redes sociales. Madrid: Arco Libros.

Proyecto MEsA. (2017). Corpus MEsA. [Recurso electrónico]. Disponible en: [http://grupo.us.es/ grupoapl/otrosapartados.php?otro=10]

Quirk, R. et al (1985). A Comprehensive Grammar of the English Language. London: Longman.

RAE y ASALE (2009). Nueva gramática de la lengua española. Morfología y sintaxis. Madrid: Espasa.

Sáez, J. S. (2007). El chat: la conversación tecnológica. Madrid: Arco Libros.

Yus, F. (2001). Ciberpragmática: el uso del lenguaje en Internet. Barcelona: Ariel. 
